\title{
Time variability management and trade-off analysis of quality, productivity, and maintenance efficiency
}

João Thiago de Guimarães Anchieta e Araujo Campos¹, Adonias Magdiel Silva Ferreira, Francisco Gaudêncion Mendonça Freires ${ }^{1}$

${ }^{1}$ Federal University of Bahia - UFBA, Polytechnic School, Department of Mechanical Engineering, Salvador, BA, Brazil.

How to cite: Campos, J.T.G.A.A., Ferreira, A.M.S. and Freires, F.G.M. (2021), "Time variability management and trade-off analysis of quality, productivity, and maintenance efficiency", Brazilian Journal of Operations \& Production Management, Vol. 18, No. 4, e20211124. https://doi.org/10.14488/BJOPM.2021.018

\section{ABSTRACT}

Goal: This research aims to examine the trade-off behaviour between productivity, quality and maintenance performance and evaluate the efficiency of the framework integrated to a time variability in operational management.

Design / Methodology / Approach: The proposed framework integrates a stochastic analysis of process and TVM to manage process variability and analyse the trade-off behaviour between quality, productivity, and maintenance efficiency. The framework generates a control chart for each workstation and analyses the operator's time to execute an assembly process for six workstations. The processes are characterised and evaluated via stochastic simulation, resulting in a trade-off analysis with a multicriteria approach.

Results: A relational graphic of performance dimensions shows that productivity and maintenance performance have a high dependency on time variability management, whereas quality has a minor impact over trade-off decisions. The proposed framework has a huge significance to operational management which allow to apply complex models to time variability analysis and organisation performance.

Limitations of the investigation: The trade-off analysis in this study is limited to a constant tradeoff model to validate the framework.

Practical implications: This framework, used in association with traditional management philosophies, is a powerful tool that permits managers to develop a trade-off analysis and make decisions on workstations. Thus, a research field that correlates time variability with performance dimensions may be validated by this framework.

Originality / Value: A framework that allows the use of MCDM to analyse the trade-off behaviour on organization performance and a trade-off analysis between performance dimensions and time variability management in operational performance.

Keywords: Trade-Off; Decision Support System; Time Variability; Discrete Production.

\section{INTRODUCTION}

Because of the complexity of the current market, where several factors are considered as necessary for competitiveness, companies must look forward beyond traditional methods to increase their efficiency. The usual management paradigms regard the manufacturing process

Financial support: None.

Conflict of interest: The authors have no conflict of interest to declare.

Corresponding author: jcampos@ufba.br

Received: 10 Dec 2020

Approved: 17 Dec 2020.

Editor: Julio Vieira Neto. 
as part of a systemic production chain, which accounts for not only processes inside the company but also all factors that affect the product delivered to the customer (Asgari et al., 2016; Wang et al., 2015). Whereas industries are looking for ways to efficiently and effectively use their resources, management strategies consider in a holistic view every activity that involves the production system. Thus, efficiency and efficacity along the production chain are the main objectives of a decision maker to reach a competitive advantage.

To increase decision efficiency, processes must be evaluated based on interaction. Thus, to achieve better results, managers should use a systemic decision over the entire production system (Andersson and Bellgran, 2015). The trade-off relation in a decision-support system (DSS) must then be considered in all organization levels. The complexity of system analysis or of the decision-making process occurs because several elements inside and outside of the organization are interrelated (Fang and Marle, 2012; Moktadir et al., 2019) Some authors explain this principle by proposing frameworks (Sant'Anna, 2015) that consider the complexity of a holistic DSS due to a large number of variables. The use of data analysis to support a decision-making process is limited by a few parameters (MacCormack et al., 2003; Franke and Ciccozzi, 2018), and, by consequence, affects the decision that is made. In this study, we analyse the trade-off behaviour between performance dimensions, evaluate the efficiency of a DSS integrated with trade-off analysis, and identify activities with a high sensitivity to valueadded interactions on the production system.

In the operational research field, mathematical models have been proposed for analysing multicriteria and multi-objective models. Multicriteria decision-making (MCDM) is a subfield of operational research that is widely used in several research areas to analyse conflict decisions and provide optimal solutions based on a large number of variables (Danesh et al., 2017; Coelho et al., 2016; Yu et al., 2018; Mardani et al., 2018; Banasik et al., 2018; Kaya et al., 2018). Vivas et al. (2020) proposes the use of analytical hierarchy process (AHP) to analyze sustainable process which inserts beyond economic factors, environment and social performance. Popovic et al. (2018) and Castro and Parreiras (2018) develop a comparative study of AHP with a large literature review of multicriteria approaches. An application of these methods to operational tasks is necessary to identify and evaluate performance indicators and drive managers to make better decisions. We propose a framework that allows the use of MCDM to analyse the trade-off behaviour on organization performance. Wang et al. (2019a) proposes an integrated method of multicriteria uses as proposed in this research, however, the integration to trade-off decisions proposed in this research collaborates more efficiently to better decisions. We also examine the trade-off behaviour between performance dimensions and evaluate the efficiency of a DSS integrated with a trade-off analysis of time variability management and operational performance. A literature review and relation with this research is important to the framework proposal and is described in the subsequent sections.

\section{Operational performance considerations}

The main performance dimensions that have an impact on the efficient and effective use of resources are cost, quality, reliability, flexibility, and speed (Santa et al., 2010). Some authors assign these dimensions to quality, productivity, and maintenance performance (Colledani et al., 2014). The decision-making process on the performance of an organization is involved in the strategic, tactical, and operational management levels. A DSS has different impacts on these management levels; for example, in a bottom-up strategy, a systemic decision, which accounts for the entire production system and not only the resolution of a specific problem, has a significant impact on the strategic-level decisions of a company. Even the current management paradigms consider strategic decisions on all management levels (Grosswiele et al., 2013). In the operational level, decisions for improving performance dimensions are handled separately (Mitra et al., 2015).

Further, to promote better results, the data and information used in a DSS are not treated as a system. Wang et al. (2019b) analyze methods and theories applied to flexible processes 
and operations which lead to significant impact on the manufacturing performance. Flexible processes is highly dependent of information system and, by consequence, the systematisation of information in a management decisions must be considered where performance dimensions will be improved and, by consequence, grant better production quality (Alan and Beckett, 2000). Furthermore, the bottom-up strategy is usually used as the management method for operational decisions. Thus, current improvement philosophies emphasise bottom-up organisational learning for continuous improvement, in a way that accounts for cross-functional communication and feedback on all organizational layers (Kim et al., 2014). Consequently, even though the strategic level defines the goals and objectives of an organization, on the operational level, the efficiency of operational decisions are required to achieve those objectives (Plaza et al., 2019).

In addition, even though operational performance is consistently involved in research about management (Parast, 2011), operations-based factors in connection to a systemic decision (Chavez et al., 2015) are not included. A cross-functional approach (Prajogo et al., 2018) to project management (Xu et al., 2014) analyses the same problems regarding decisions over an entire system (Proehl, 1996; Emery, 2009; Santa et al., 2010; Popoli, 2019; Puche et al., 2016). A DSS based on the main performance dimensions is required in the operational level but has not been considered in past studies.

\section{Trade-off and unbalanced systems relationship}

The alignment between operations and trade-off behaviour is essential to management decisions (Parast, 2011). For example, quality improvement impacts maintenance tasks and production planning (Weiss et al., 2018; Rivera-Gómez et al., 2020). Based on Gardner (2020), where it focus on understanding the trade-off between feedback on conformance quality and production speed, a slack in resources which represents cost to an organization is also regarded as a trade-off relation and is inherent to or inevitable in a process (Madapusi and D'Souza, 2012; Parast, 2011). When the impact of a decision on each of the performance dimensions are then involved, it is also a trade-off relation (Rosenzweig and Easton, 2010; Mrad et al., 2019). This systemic view is recognized by managers at a strategic level but not evident in operational decisions. In general, improvement based on a non-systemic relation causes negative impact over the whole production system. Those decisions cause the system to become unbalanced in different manners (Kempenaers et al., 1996); for example, operations planning and scheduling under the assumption of equipment being permanently available will be unbalanced by disruptions to the manufacturing operation (Negahban and Smith, 2014; Aghezzaf et al., 2007; Gebennini et al., 2017). This example shows clearly how a trade-off relation must be included in the decision-making process.

In general, unbalanced systems are caused by non-systemic decisions. Because of the several parameters considered in a DSS that support the analysis of a problem, the complexity of a decision-making model can cause system disruptions. In improvement philosophies, such as Lean Manufacturing or Six Sigma, measurement, control, and improvement do not have the same results regarding each of the performance dimensions.

Thus, the integration of a trade-off relation into the DSS must be considered. Even when it is substantially complex to analyse a considerable number of parameters to solve specific problems (Sant'Anna, 2015), fewer or wrong parameters will not permit decisions toward improvement to be made (Bokrantz et al., 2018). On a large scale, this condition will have critical impact on system balance and on its high sensitivity to problem-solving parameters, specifically in process control and analysis. Thus, when this relation is included into DSS parametrization, a systemic model toward efficiency, as an improvement solution, will be reached.

\section{Time variability management (TVM)}

For many of the usual parameters in industrial management, time analysis is used in almost all improvement methods (Prajogo et al., 2018; Neha and Ashutosh, 2017). Time 
variability is considered a problem by managers because it causes operational problems, such as bottlenecks, equipment failures, or product defects (Montgomery, 2019; Sousa et al., 2018). In an analytical approach, time variability is a parameter to be controlled because it is critical in making decisions on productivity performance and, consequently, profitability. Despite the existence of several studies regarding techniques and methods on time variability reduction, the use of these methods in ways that involve the trade-off decision is still unexplored (Kannan and Tan, 2005). Then, time variability management (TVM) is beyond than time variability reduction, where it also includes in the systemic approach the time variability behavior to grant control of the process, and consequently promotes better results to the entire production system and not only for a specific problem-solving task. Therefore, TVM is beyond parameter analysis to reduce process time; it collaborates with the rest of the system as a competitive advantage tool to produce better results in the decision-making process.

Because of the complexity of the DSS, stochastic analysis of variability reduction efforts is considered (Ferro et al., 2017; Yegul et al., 2017; Layeb et al., 2018). TVM is a helpful tool for improving the process in a systemic approach. Traditionally, companies engage in stochastic studies by developing deterministic models to support their decision (Karmarkar and Kekre, 1987; Ahmed and Beauchamp-EIMaraghy, 2013; Yang et al., 2018), but involve little variability analysis in their key performance indicators. Authors argue about the use of stochastic behaviour (Schardong et al., 2018) to develop parameters to be used as measurements in the production system. For example, before the use of discrete simulation, performance indicators were calculated via descriptive statistics and then used as indicators to propose changes. TVM involves stochastic and deterministic analyses that account for variability and trade-off relations, which is different from traditional management that seeks reduction of time variability without regard for any trade-off relations, which, by consequence, decreases decision efficiency. Furthermore, TVM manages variability by involving trade-off relations between performance dimensions and deterministic parameter behaviour concerning the entire system (Choe et al., 1997).

\section{FRAMEWORK PROPOSAL}

The use of TVM as a competitive advantage is a solution for creating better decisions under current management paradigms. In this study, we seek to examine a decision tool using traditional improvement methods and involve collaboration with the rest of the production system through the development of a new DSS tool that considers trade-off relations in the decision-making process. Through the use of TVM as a necessary condition for making better decisions, a trade-off analysis is expected to be incorporated.

This analysis comprises a systemic and multicriteria approach to support better management decisions regarding performance dimensions. The systemic approach is defined with consideration for qualitative and quantitative relations, using analytical methods for TVM and empirical approach to multi-criteria decisions.

This model has three premises, which consolidate the decision-making framework:

1. Bottom-up decisions, i.e., decisions are made from the operations-based level and are used to the higher levels according to their needs.

2. The framework allow to insert a large number of performance factors but to validate in this research the quality, productivity and maintenance dimensions are defined by Colledani et al. (2014).

3. Output of this framework results in a trade-off analysis that supports the decision process into the operational management level.

According to the literature, strategic decisions have different sensibilities into the lower levels (i.e., tactical and operational), which can result in negative effects when these decisions are regarded separately without consideration for the impact on all performance dimensions. At present, the concept of operational decisions does not consider trade-off relations and is dependent on operators that need to execute, monitor, or adjust equipment (Müller and Oehm, 2019; El Mouayni et al., 2020). For example, decisions made regarding quality, 
productivity, and maintenance do not account for aspects that involve systemic decisions between these areas. Figure 1 shows a traditional decision-support model involving productivity, quality, and maintenance decisions.

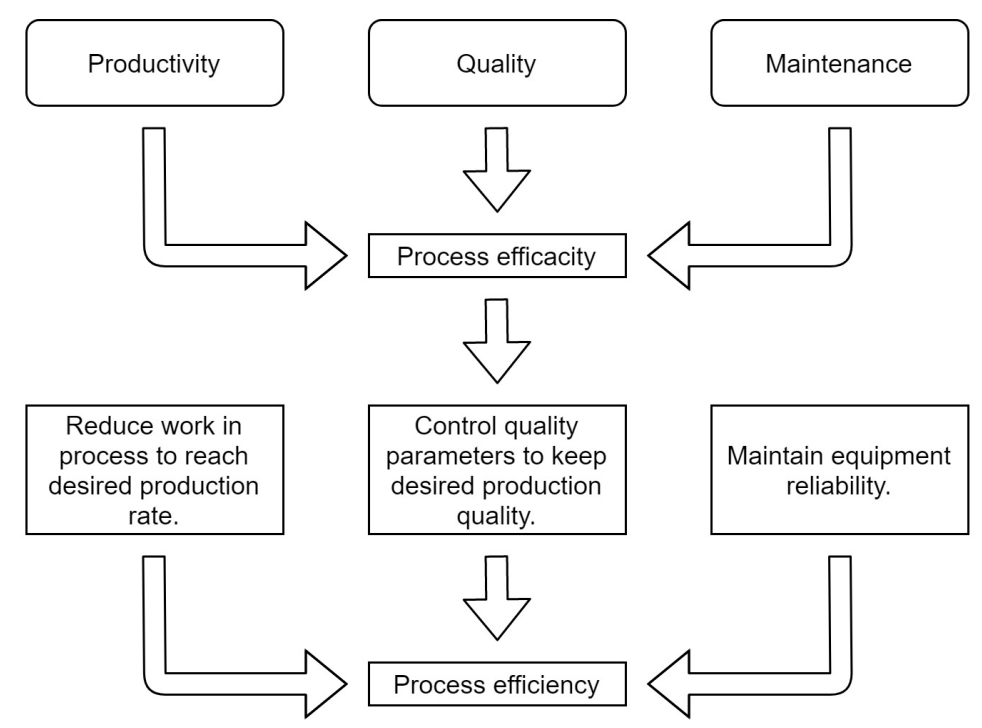

Figure 1: Traditional decision structure. Source: Authors

To achieve process efficiency, each of the performance dimensions has a 'stand-alone' decision-making model (Swink et al., 2005). Furthermore, to improve a DSS at an operationsbased level, trade-off relations between the areas involved must be considered. The relationships between quality, productivity, and maintenance are defined based on common parameters in the decision-making process, where the impact over each of the parameters is examined (Tan and Wang, 2010). This approach considers a holistic view of the organization, which is different from existing improvement philosophies that include systemic relations between processes but do not use, for example, analytical tools to perform a holistic analysis (Sartal et al., 2017). Thus, the decision framework has the common parameters of each of the performance dimensions (Arinez et al., 2010; Robson et al., 2013; Weinstein and Chung, 1999; $\mathrm{Hu}$ and $\mathrm{He}, 2014$ ) and supports the conceptual model shown in Figure 2.

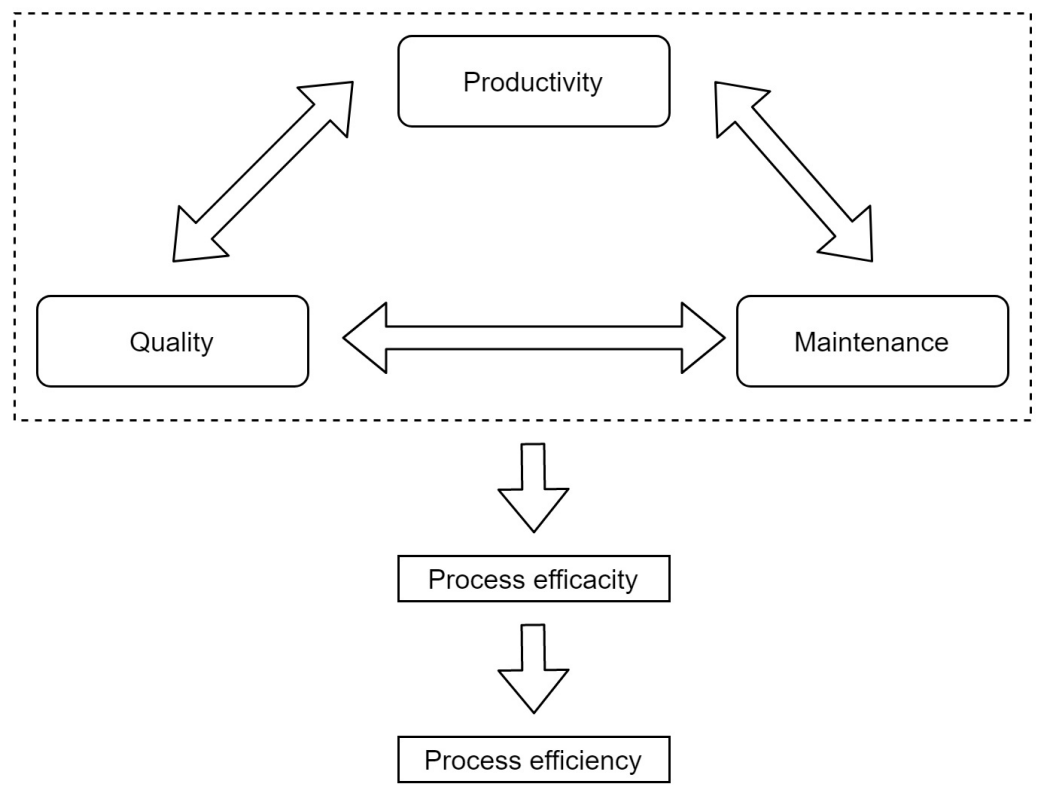

Figure 2: Trade-off decision structure involving performance dimensions. Source: Authors 
The proposed framework includes the concepts of TVM and trade-off analysis into a realtime data analysis by integrating a system for assisting operators in the execution of tasks, as defined in Figure 3.

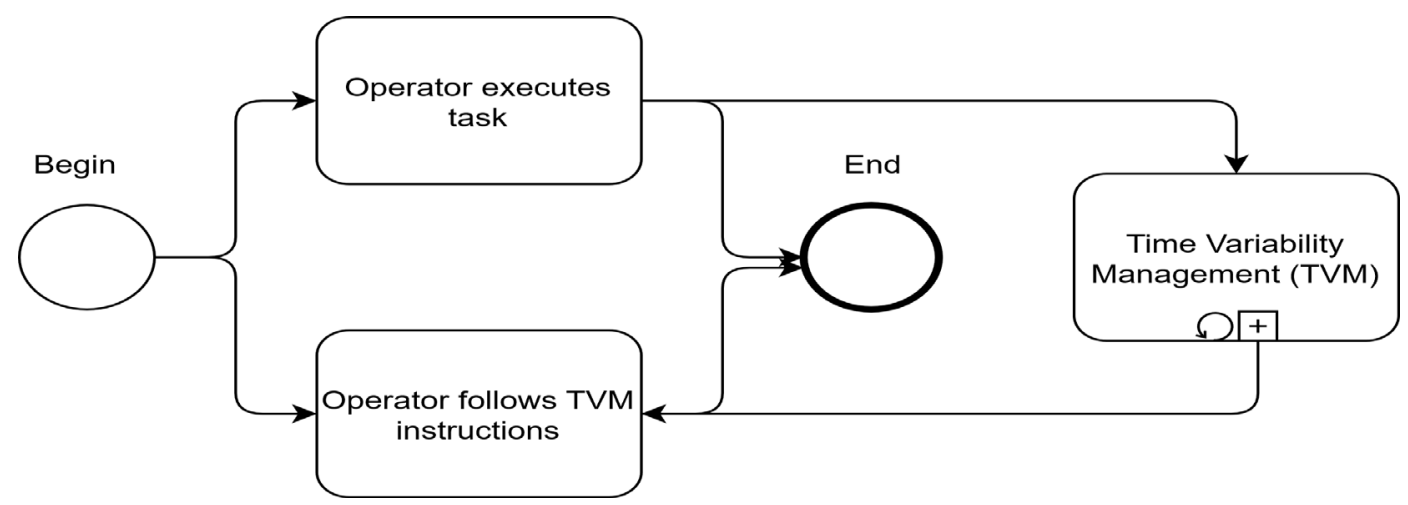

Figure 3: Operator decisions assisted by TVM. Source: Authors

This DSS tool then analyses the data of operations by modelling the relationships between operators, resources, and time. Further, the framework generates a trade-off analysis for each operation-based activity to identify the process efficiency in terms of the performance dimensions. The framework structure is illustrated in Figure 4.

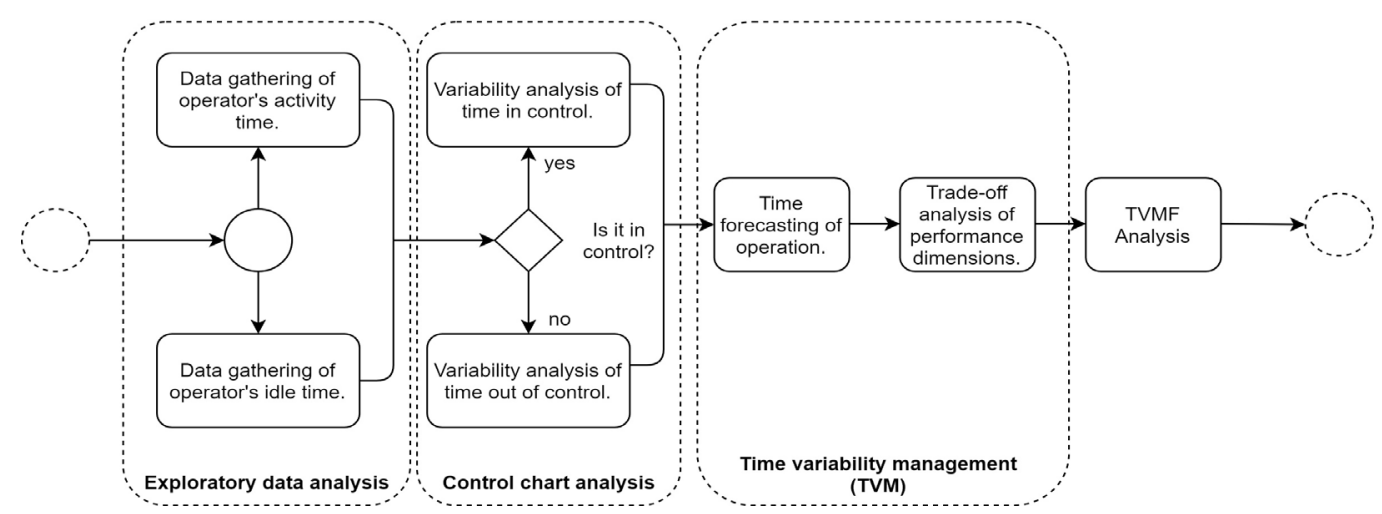

Figure 4: Proposed framework of Time Variability Management. Source: Authors

\section{Process characterization}

A single operation time is represented by Equation 1

$Q_{e i o}=\sum_{i=0}^{1} / T_{e i o}-T_{(e-1) i o}$,

where:

$T$ : continuous elapsed,

$Q$ : Single operation time (activity or idleness)),

$e:$ measured time index,

$i:$ measured time type index( 1 for activity time and 0 for idle time),

$o:$ Operation index for a single operator (if it is an unique operation, the index is 0 ),

$n$ : sample size.

Time is gathered using a chronometer by a continuous time measurement. Process time $P$ is the time necessary to execute the process from begining to end, operation time $Q$ is the 
time of activity (operator executes the task) or idleness (operator does not executes the task). When operator does an activity ( $Q$ with $\mathrm{i}=1)$ ) or stop it for any reason that results in idleness $(Q$ with $\mathrm{i}=0$ ), the operation time $Q$ is measured. Then, process time, which is the total time of all activity and idleness, is then calculated using Equation 2.

$P=\sum_{l}^{o} \sum_{l}^{e=n} \sum_{i=0}^{1}\left(T_{e i o}-T_{(e-1) i o}\right)$ follows:

Thus, the gathered sample is characterized via descriptive and inferential statistics as

\section{Probability distribution fitting}

To characterize the operations behaviour, chi-squared statistical distribution is used to fit the gathered data to a probability distribution, and quartile analysis is applied to identify outliers. The outliers are a 1.5 quartile deviation from the first or third quartile. An interval estimation of mean parameter is then defined to verify if the sample is representative of the population:

$$
\chi^{2}=\sum_{\text {all classes }} \frac{\left(Q_{e i o}-v_{e i o}\right)^{2}}{v_{\text {eio }}},
$$

where:

$v$ : expected time into chi-squared distribution.

The parameters used to fit the probability distribution are $\chi^{2}$ and the number of degrees of freedom, which is the sample size. Thus, the hypothesis for testing the probability distribution are

$\mathrm{HO}$ : observed values are equal to the theoretical values (probability distribution),

$\mathrm{Ha}$ : observed values are not equal to the theoretical values (probability distribution).

A likelihood-ratio test (Mackenzie et al., 2018), which is used to evaluate the hypotheses, is defined as

$$
L R T=-2 \ln \left(\frac{L\left(\hat{\theta}_{0} \mid \chi\right)}{L\left(\hat{\theta}_{A} \mid \chi\right)}\right)
$$

where $\hat{\theta}_{0}$ and $\hat{\theta}_{A}$ are the maximum likelihood estimation (MLE) of each distribution. The null hypothesis is accepted if the $p$-value test over $(\alpha)$ is higher than 0.05 .

\section{Time variability management}

The data analysis uses control chart theory to identify activities, operations, or process anomalies. A control chart for idle time and activity time is then calculated using

$$
\begin{aligned}
& U C L=\mu+3\left(\sigma_{\bar{Q} e i o}\right), \\
& L C L=\mu-3\left(\sigma_{\bar{Q} e i o}\right) .
\end{aligned}
$$

Through the use of the central limit theorem, where $\bar{Q}_{i o}$ is normally distributed, the upper control limit (UCL) and lower control limit ( $(\mathrm{CL})$ are defined as the boundaries of the trusted interval. In this study, the three-sigma control limits are considered (Montgomery, 
2019). Variability analysis is performed in three distinct steps: mapping, modelling, and forecasting analysis.

Mapping and modelling

A discrete event modelling tool is required. From among known such methods, the Petri net, which is a wide and solid discrete event modelling tool, is used in this study. It is a graphical and mathematical modelling tool for discrete event processes used to describe and analyse systems (Murata, 1989; Başak and Albayrak, 2015; Drakaki and Tzionas, 2017). The Petri net is a 5-tuple, i.e., $P N=\left(P, T, F, W, M_{0}\right)$,

where:

$P=\left\{p_{1}, p_{2}, \ldots, p_{m}\right\}$ is a finite set of places,

$T=\left\{t_{1}, t_{2}, \ldots, t_{n}\right\}$ is a finite set of transitions,

$F \subseteq(P \times T) \cup(T \times P)$ is a set of arcs (flow relation),

$W: F \rightarrow\{1,2,3, \ldots\}$ is a weight function,

$P \cap T=\varnothing$, and $P \cup T \neq \varnothing$.

Thus, to map the process, the Petri net model is simplified to a 3-tuple, $M=(P, T, F)$, represented by a generic $C$ matrix of places and transitions:

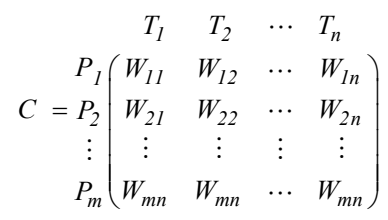

To simulate the system dynamic behaviour, a Petri net must comply with the firing rule (Murata T., 1989), which is defined as

$\forall p \subset P, M^{\prime}=M+C(., t)$

A decision matrix $D$ for reducing the variability based on the coefficient of variation and the relation with the time variability management factor (TVMF) is proposed and calculated as shown in equation Murata (1989).

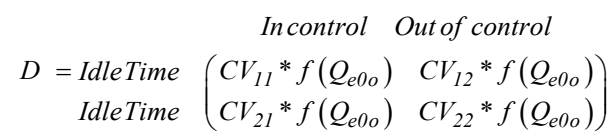

where:

$C V$ : coefficient of variation,

Time variability management factor (TVMF) is defined by the maximum value of variability between activity time and idle time of the same operation. The maximum value is then selected for the trade-off performance analysis, which is represented by

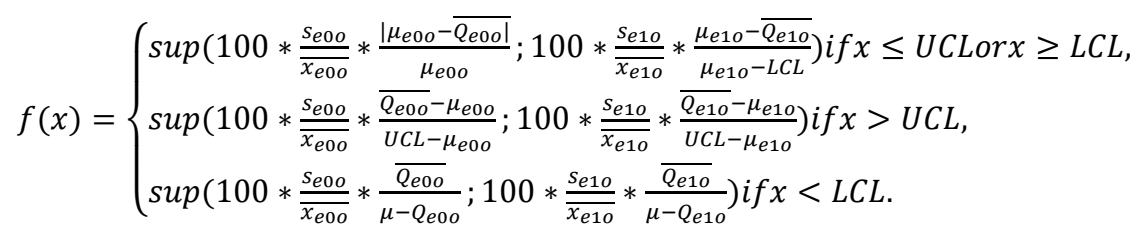




\section{Trade-off performance analysis}

To trace the forecasting behaviour at each operation time and generate a trade-off analysis, the proposed framework is based on matrix 8 via the analysis of the time variability model inside the control chart limits. Thus, the model analyses the variability behaviours and their relations over TVMF.

The framework output is the trade-off score of Table 1, based on the following rules:

- If $x_{(\text {simulated })} \geq \mu$, then propose decrease in operation time and insert the trade-off scores of the downward arrow column in trade-off analysis model.

- If $x_{(\text {simulated })} \leq \mu$, then propose increase in operation time and insert the trade-off socres of the upward arrow colmun in trade-off anlaysis model.

Table 1 - Trade-off scores. Source: Authors

\begin{tabular}{ccccc}
\hline & Idle Time & \multicolumn{2}{c}{ Activity Time } \\
\hline & $\uparrow$ & $\downarrow$ & $\uparrow$ & $\downarrow$ \\
\hline Quality & 0.1 & 0.3 & 0.7 & 0.2 \\
\hline Productivity & 0.15 & 0.6 & 0.1 & 0.8 \\
\hline Maintenance & 0.75 & 0.1 & 0.2 & 0.0 \\
\hline
\end{tabular}

The scores in Table 0 are constant to validate the proposed DSS tool via the generation of a trade-off relation for each new event that occurs in the process. The constant values are defined via an interview by specialists with the company staff. An analytical hierarchy process (AHP) model is used to calculate the responses consistency and ehe Delphi method is then used to validate the interview answers (Okoli and Pawlowski, 2004).

The proposed framework can decrease or increase the operation time in the examination for time variability reduction, given the trade-off relationships between time variability and quality, productivity, and maintenance performance.

\section{RESULTS AND DISCUSSION}

To validate the proposed framework, this DSS was applied to a computer components assembly company in Brazil at São Paulo city, which produces a thousand computer components box per day. The components assembly is defined in a process map as shown in Figure 5. Each workstation has an activity of the assembly process where it begins by receiving components and ends by a computer component box. The DSS get the operation time of each workstation in real time and executes the proposed structure as described in the framework section.

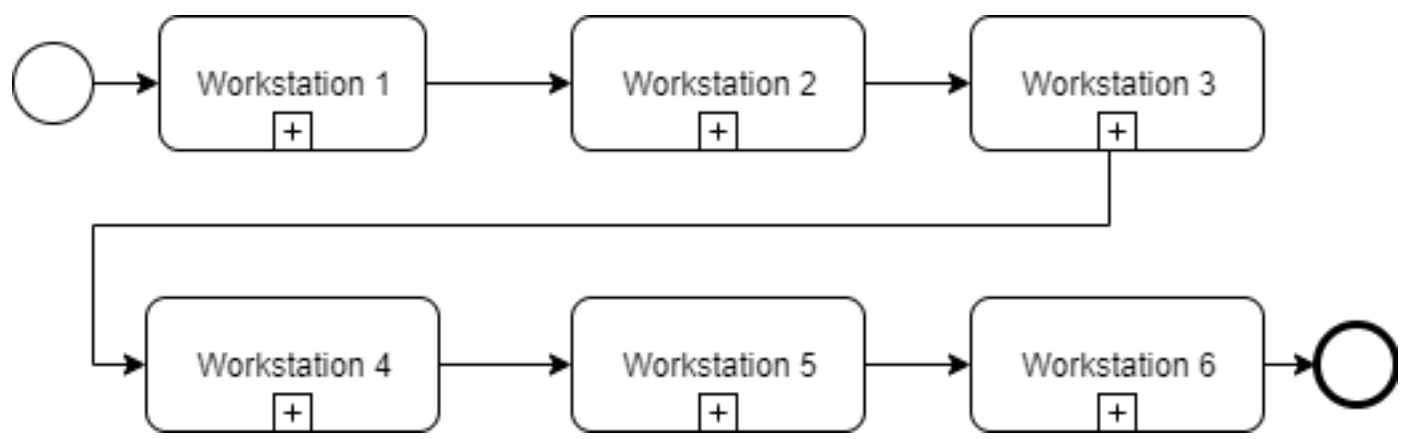

Figure 5: Process map of computer component assembly. Source: Authors 


\section{Process characterisation}

Each workstation has a specific task described using places/transitions descriptions, as outlined in Tables 2 and 3.

Table 2 - Description table for places. Source: Authors

\begin{tabular}{ccc}
\hline Name & Places & Description \\
\hline Workstation 1 & P1 & Materials in conveyor \\
\hline Workstation 2 & P2 & Components separated on the table \\
\hline Workstation 3 & P3 & Components without labels and tag \\
Workstation 4 & P4 & Components with security tag and labels \\
\hline Workstation 5 & P5 & Components with warranty tag \\
\hline Workstation 6 & P6 & Components packed \\
\hline End of process & P7 &
\end{tabular}

Table 3 - Description table for transitions. Source: Authors

\begin{tabular}{ccc}
\hline Name & Transitions & Description \\
\hline Workstation 1 & T1 & Pick and Positioning \\
\hline Workstation 2 & T2 & Cleaning Components \\
Workstation 3 & T3 & Organizing Components \\
\hline Workstation 4 & T4 & Labelling Components \\
\hline Workstation 5 & T5 & Components Warranty procedures \\
\hline Workstation 6 & T6 & Packing procedures. \\
\hline
\end{tabular}

A sample of 100 events of each activity (transition 1 to 6 ) is gathered from the process using the proposed framework. Then, Table 4 is a descriptive statistics containing the results of statistics tests for validating the data sample gathered.

Table 4 - Descriptive statistics of each activity time in each workstation of the process. Source: Authors

\begin{tabular}{ccccccc}
\hline Name & $\begin{array}{c}\text { Sample } \\
\text { Size }\end{array}$ & Mean & $\begin{array}{c}\text { Standard } \\
\text { Deviation }\end{array}$ & $\mathbf{1}^{\circ}$ Quartile & $\mathbf{3}^{\circ}$ Quartile & $\begin{array}{c}\text { Interval } \\
\text { Estimation }\end{array}$ \\
\hline Workstation 1 & 100 & 20.39 & 1.61 & 19.2 & 21.775 & $20.12 ; 20.66$ \\
\hline Workstation 2 & 100 & 3.73 & 0.39 & 3.5 & 4.075 & $3.66 ; 3.79$ \\
\hline Workstation 3 & 100 & 13.32 & 0.72 & 12.8 & 13.8 & $13.20 ; 13.44$ \\
\hline Workstation 4 & 100 & 2.70 & 0.49 & 2.3 & 3.1 & $2.62 ; 2.78$ \\
\hline Workstation 5 & 100 & 4.37 & 0.55 & 3.93 & 4.78 & $4.27 ; 4.45$ \\
\hline Workstation 6 & 100 & 4.44 & 0.60 & 4 & 5 & $4.34 ; 5.53$ \\
\hline
\end{tabular}

\subsection{Time variability management}

The process has been modelled using the Petri net tool, resulting in the matrix represented as Matrix 3.2,

\begin{tabular}{|c|c|c|c|c|c|c|c|}
\hline & \multicolumn{2}{|c|}{$\begin{array}{ll}T_{1} & T_{2}\end{array}$} & $T_{3}$ & $T_{4}$ & $T_{5}$ & $T_{6}$ & $\Gamma_{7}$ \\
\hline$D$ & -1 & 0 & 0 & 0 & 0 & 0 & \\
\hline$P_{2}$ & 1 & -1 & 0 & 0 & 0 & 0 & 0 \\
\hline$P_{3}$ & 0 & 1 & -1 & 0 & 0 & 0 & 0 \\
\hline$P_{4}$ & 0 & 0 & 1 & -1 & 0 & 0 & 0 \\
\hline$P_{5}$ & 0 & 0 & 0 & 1 & -1 & 0 & 0 \\
\hline$P_{6}$ & 0 & 0 & 0 & 0 & 1 & -1 & 0 \\
\hline & 0 & 0 & 0 & 0 & 0 & 1 & -1 \\
\hline
\end{tabular}


and represented graphically as Figure 6:

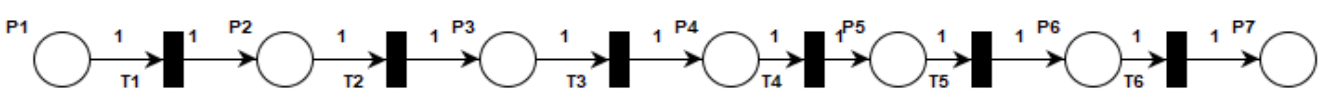

Figure 6: Petri net of computer components assembly. Source: Authors

The statistical model of each workstation with a stochastic probability approach is represented. Tables 5 and 6 show the probability function parameters of each workstation and the likelihood ratios used in the hypothesis test validation. Figure 7 shows the data behavior of each sample of workstation 1 to workstation 6 .

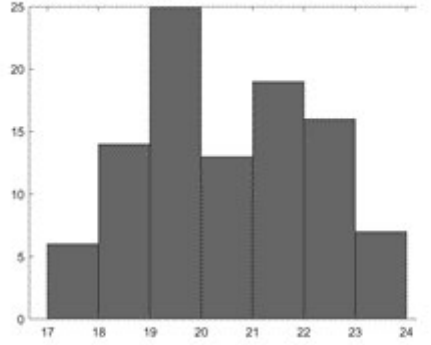

(a)

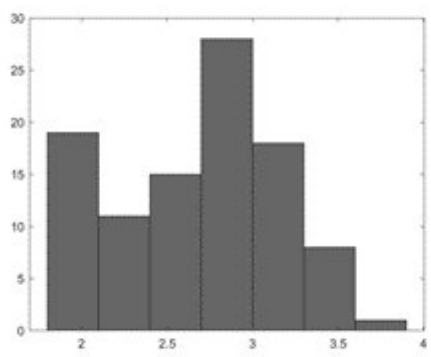

(d)

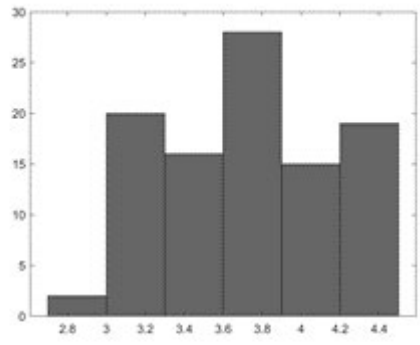

(b)

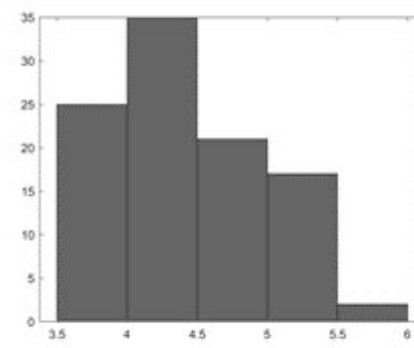

(e)

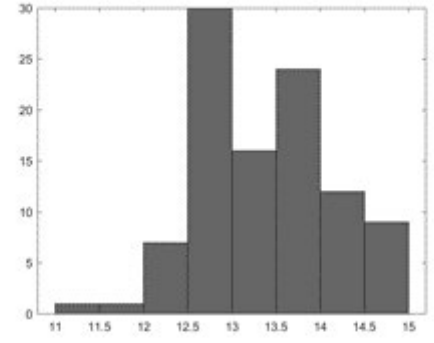

(c)

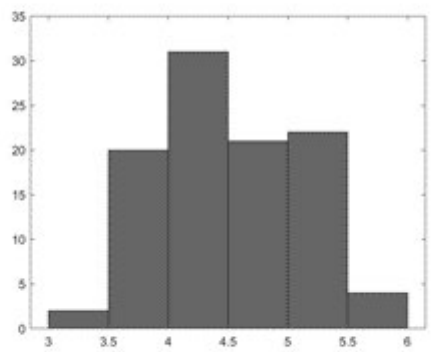

(f)

Figure 7: Histograms of workstation process time: a) Workstation 1, b) Workstation 2, c) Worksation 3, d) Workstation 4, e) Workstation 5, f) Workstation 7. Source: Authors

Table 5 - Activity-time probability distribution parameters of each workstation. Source: Authors

\begin{tabular}{cccc}
\hline Workstation & Probability Function & Parameters & Log Likelihood \\
Workstation 1 & Normal & $2.049 \mathrm{e}+01 ; 1.548 \mathrm{e}+00$ & $-7.424 \mathrm{e}+01$ \\
\hline Workstation 2 & Normal & $3.815 \mathrm{e}+00 ; 3.568 \mathrm{e}-01$ & $-1.553 \mathrm{e}+01$ \\
\hline Workstation 3 & Gamma & $4.404 \mathrm{e}+02 ; 3.042 \mathrm{e}-02$ & $-3.877 \mathrm{e}+01$ \\
\hline Workstation 4 & Normal & $2.732 \mathrm{e}+00 ; 4.921 \mathrm{e}-01$ & $-2.840 \mathrm{e}+01$ \\
\hline Workstation 5 & Gamma & $6.289 \mathrm{e}+01 ; 7.283 \mathrm{e}-02$ & $-3.459 \mathrm{e}+01$ \\
Workstation 6 & Gamma & $6.301 \mathrm{e}+01 ; 6.912 \mathrm{e}-02$ & $-3.253 \mathrm{e}+01$ \\
\hline
\end{tabular}

The distributions for all workstations are validated using normal and gamma probability distributions. Generally, discrete production time is distributed by a normal probability function, as defined for workstations 1, 2, and 4. However, a gamma distribution has 
similarities with exponential distribution, which indicates that workstations 3, 5, and 6 have non-normal behaviours and significant impacts on variability analysis.

Table 6 - Idle-time probability distribution parameters of each workstation. Source: Authors

\begin{tabular}{cccc}
\hline Workstation & Probability Function & Parameters & Log Likelihood \\
\hline Workstation 1 & Gamma & $2.580 \mathrm{e}+00 ; 3.686 \mathrm{e}-01$ & $-3.011 \mathrm{e}+01$ \\
\hline Workstation 2 & Gamma & $1.589 \mathrm{e}+00 ; 5.154 \mathrm{e}-01$ & $-2.974 \mathrm{e}+01$ \\
\hline Workstation 3 & Gamma & $1.430 \mathrm{e}+00 ; 5.760 \mathrm{e}-01$ & $-3.082 \mathrm{e}+01$ \\
\hline Workstation 4 & Gamma & $4.081 \mathrm{e}+00 ; 3.236 \mathrm{e}-01$ & $-3.628 \mathrm{e}+01$ \\
\hline Workstation 5 & Gamma & $1.971 \mathrm{e}+00 ; 7.940 \mathrm{e}-01$ & $-5.344 \mathrm{e}+01$ \\
\hline Workstation 6 & Gamma & $1.425 \mathrm{e}+00 ; 1.320 \mathrm{e}+00$ & $-6.389 \mathrm{e}+01$ \\
\hline
\end{tabular}

Following the framework proposal, a petri net simulation has been executed using GPENSIM Petri Net Tool for Mathlab (Davidrajuh, 2018). The Petri net graphic allows the identification of process bottlenecks and activity time variabilities for each workstation.

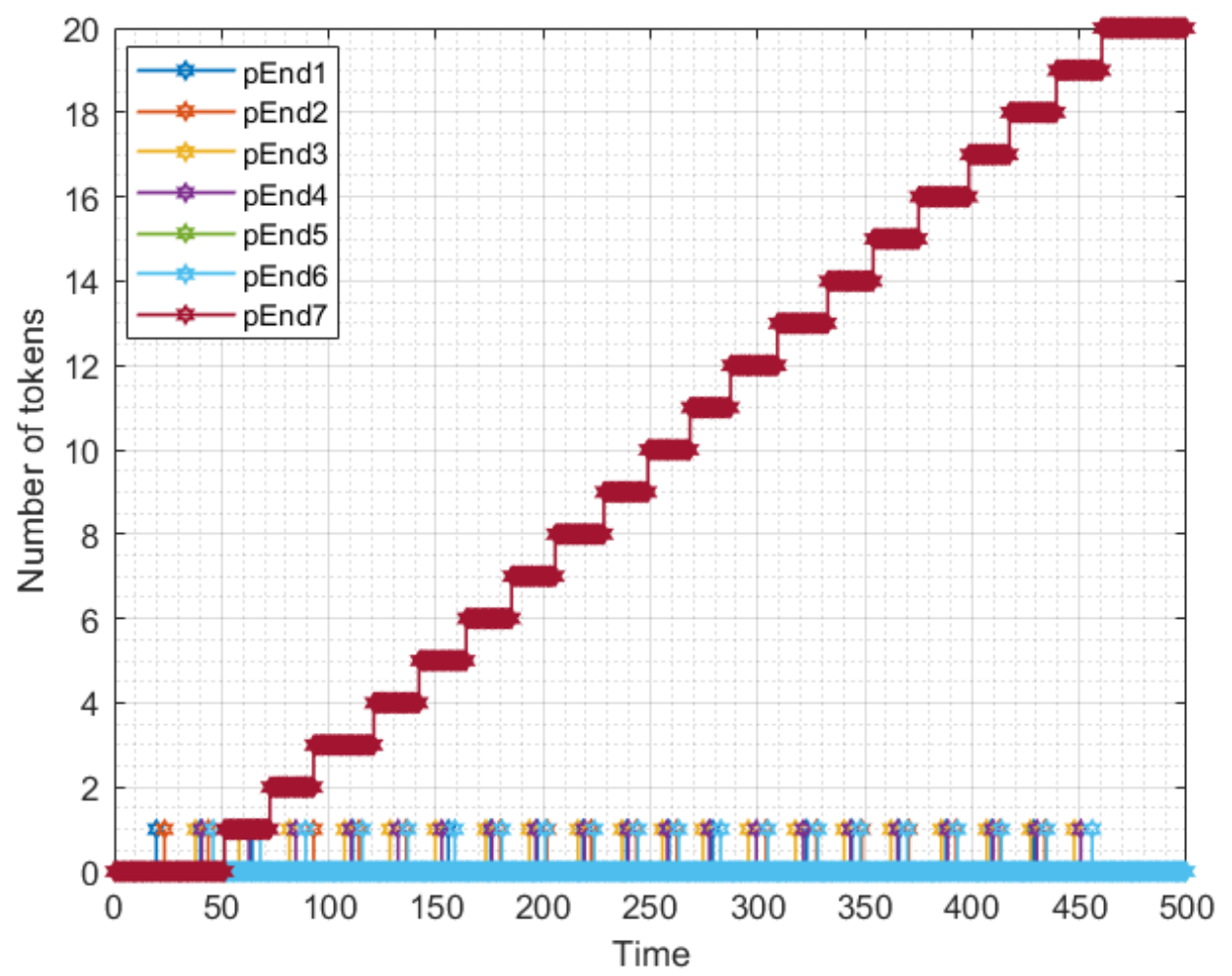

Figure 8: Petri net simulation. Source: Authors

The assembly process has been modelled based on the activity and idle times of each operator as represented in Figure 8. Time has been gathered in real time using a sample of 100 events. For each workstation, process times have been added into a simple control chart, which permits a comparison between real time and simulation time.

The control chart represented as Figure 9 and 10 shows the process behaviour for each workstation. It is possible to identify the deviation between real and simulated times, where it affects the trade-off analysis results. Based on the variability behaviour being a decision parameter, the framework analyses the variability of each activity proposed through time variability management, as shown in Figures 9 and 10. 
It is possible to identify out-of-control operations at simulated times. The unbalanced system reveals the operator behaviour, and then a self-correction is proposed by the framework. The comparison between simulation and real time is necessary because of the framework proposal; the simulation error over real time is used to define the behaviour of the operator. The framework uses the simulation deviation to perform self-corrections in tradeoff relations and, by consequence, to further decisions that support managers. The workstations are stabilized, and then the framework proposes the use of variability reduction to produce a better trade-off decision. Figure 10 shows the real and simulation idle times for each activity.
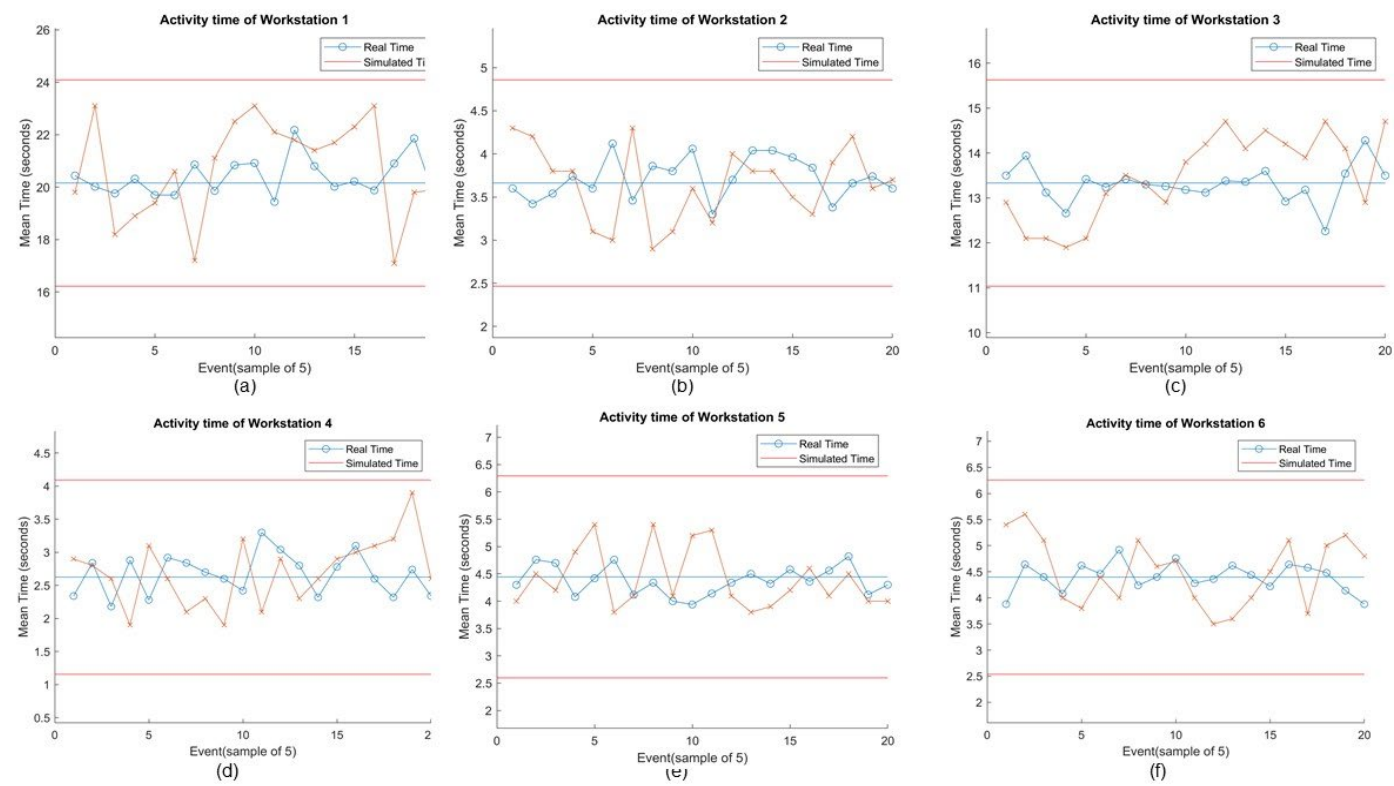

Figure 9: Activity times for each workstation. a) Workstation 1, b) Workstation 2, c) Workstation 3, d) Workstation 4, e) Workstation 5, f) Workstation 6. Source: Authors

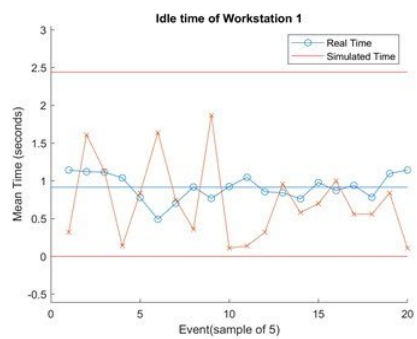

(a)

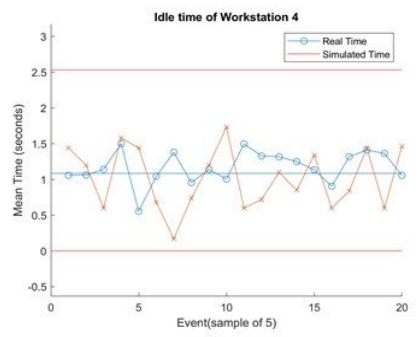

(d)

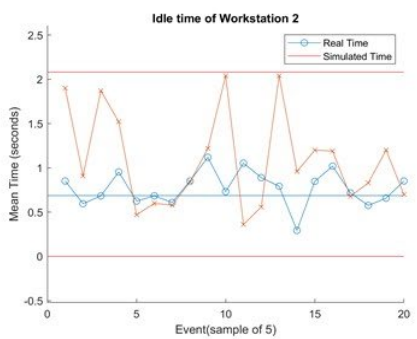

(b)

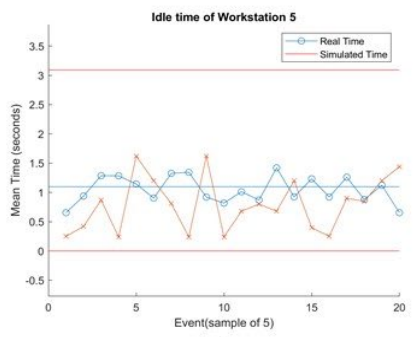

(e)

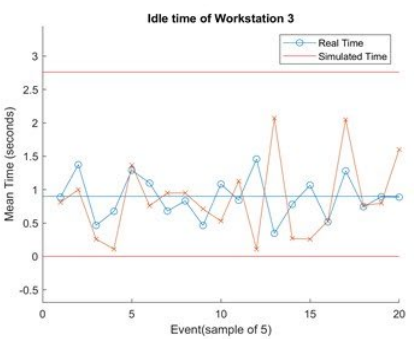

(c)

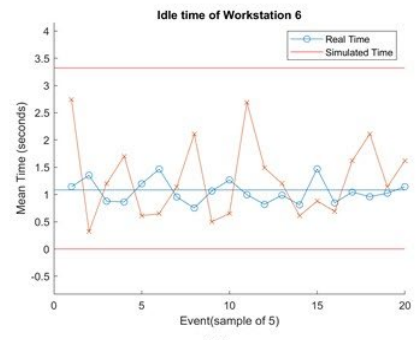

(f)

Figure 10: Idle times for each workstation. a) Workstation 1, b) Workstation 2, c) Workstation 3, d) Workstation 4, e) Workstation 5, f) Workstation 6. Source: Authors 
Thus, the analysis of real- and idle-time simulation allows the calculation of the coefficient of variation and TVMF to define a variability relation. The main purpose of this step is to identify the highest variability over the recent tasks of the operators. Figure 11 shows the trade-off scores selected for each event following the framework rules described into framework proposal section based on TVMF scores defined in Table 7.

The variability in Figure 11 is a representation of the framework proposal, the trade-off scores per event using TVMF, and shows how workstation variability affects the decisions of an organization. As shown in the figure, the variability of performance factors is a response from the framework algorithm to identify trade-off decisions. A variability self-correction is proposed, wherein higher process variability, as shown in Figure 11b, 11c, and 11e, indicates which operations have a critical impact on decision-making and, by consequence, are more value-additive and sensible for the organization, resulting in the trade-off scores of the framework output.

Figures $11 \mathrm{a}, 11 \mathrm{~d}$ and $11 \mathrm{f}$ visualise stable processes with more constant trade-off impacts over the decision-making, which allow better decisions to be made and improvement points on the process to be identified, based on the principle that improvement must be relative to a stable or controlled process.

Thus, this framework is useful for identifying which activity is more sensitive to process changes or process variability and, if it has a constant variability, improvement points.

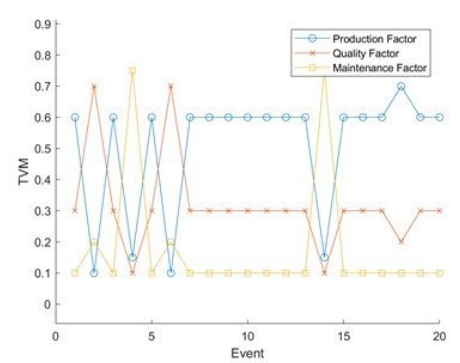

(a)

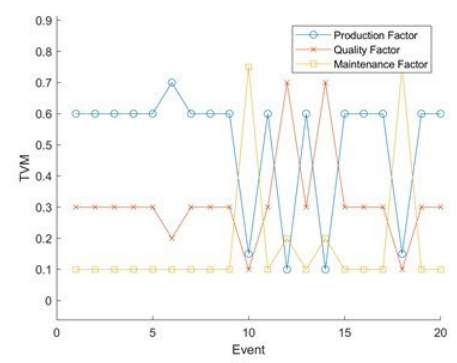

(d)

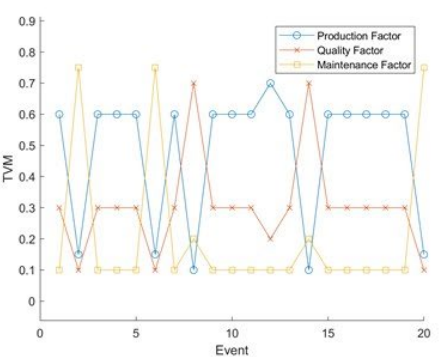

(b)

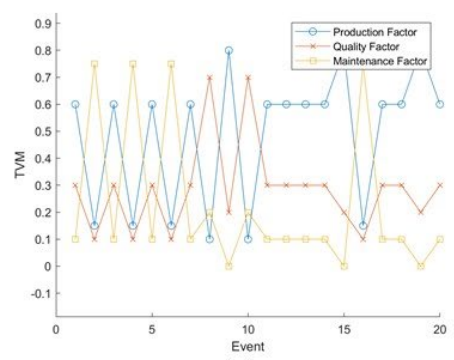

(e)

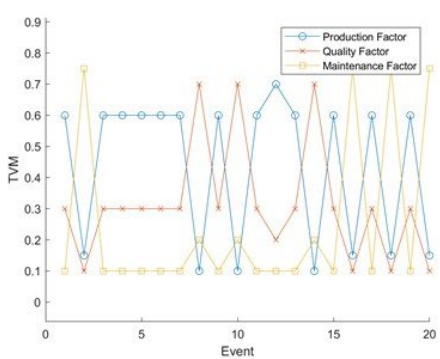

(c)

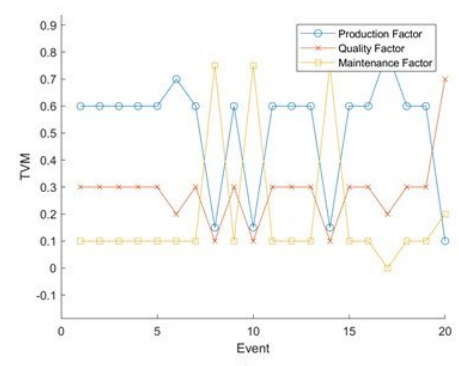

(f)

Figure 11: Trade-off factor of each workstation. a) Workstation 1, b) Workstation 2, c) Workstation 3, d) Workstation 4, e) Workstation 5, f) Workstation 6. Source: Authors

Table 7 - Trade-off analysis parameters. Source: Authors

\begin{tabular}{cccc}
\hline Workstation & Quality & Productivity & Maintenance \\
Workstation 1 & 0.29 & 0.5 & 0.25 \\
\hline Workstation 2 & 0.25 & 0.54 & 0.19 \\
\hline Workstation 3 & 0.27 & 0.49 & 0.23 \\
\hline Workstation 4 & 0.26 & 0.54 & 0.19 \\
Workstation 5 & 0.27 & 0.54 & 0.18 \\
\hline Workstation 6 & 0.25 & 0.51 & 0.23 \\
\hline
\end{tabular}


Based on an analysis of Figure 12 and a comparison of the trade-off relation (blue line) with a constant performance dimension (red line), productivity has a significant impact when variability management is involved. The quality performance dimension is not affected by TVM, which signifies that this process is adding value to the process in this dimension; changes in the process for the sake of improvement will have lower impact on the quality performance of the organization. The maintenance dimension has a high trade-off relation with productivity. For maintenance performance, the time variability management is considered to have a low impact on the management of decisions.

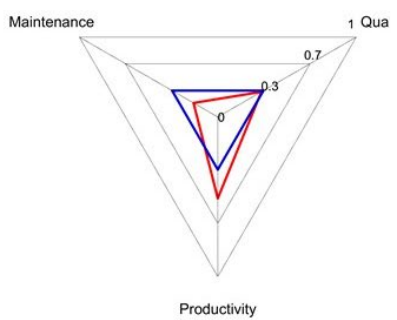

(a)

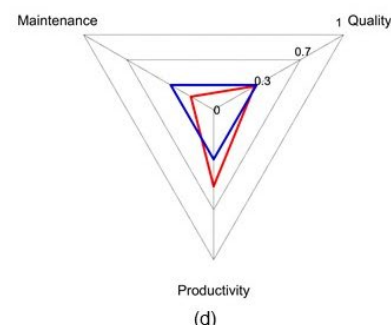

(d)

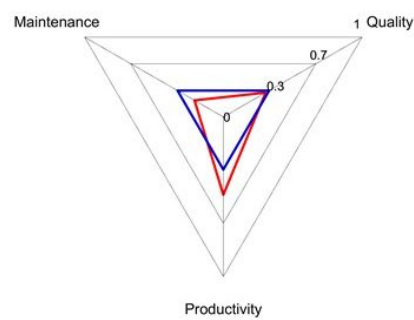

(b)

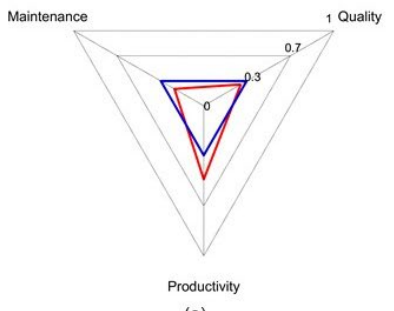

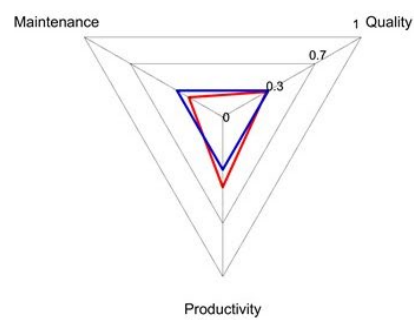

(c)

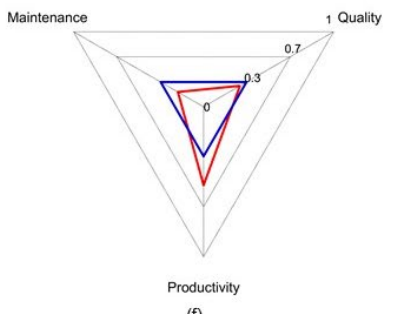

Figure 12: Trade-off analysis of each workstation. a) Workstation 1, b) Workstation 2, c) Workstation 3 , d) Workstation 4, e) Workstation 5, f) Workstation 6. Source: Authors

Thus, the proposed analysis generates the following benefits for operations-based processes:

- Process behaviour is followed in real time based on a dynamic control chart as shown as Figure 9 and 10. A dynamic control chart allow managers to identify process anomalies, corrective actions and execute preventive decisions.

- Trade-off analysis, identifying which dimension performances are prioritized in each workstation, is defined. It allow to identify which performance is prioritized in each activity and identify conflicted decisions as shown as Figure 12.

- Improvement decisions are analysed based on a trade-off view, following the trade-off analysis. Based on the principle that improvement must be relative to a stable or controlled process, the framework allow to more efficient decisions in activities wellknown described statistically and empirically.

- Trade-off relations between all performance dimensions and operator behavior on the process are defined.

\section{CONCLUSIONS}

In this study, we propose a DSS tool for managing time variability and trade-off relations in operational level management. The proposed method then generates a control chart and analyses the relation between the time variability of each workstation and the performance dimensions of the organization. By analysing the process behaviour of each workstation using the proposed framework, the quality performance has a low impact over the process. Productivity and maintenance performances have a high correlation with TVM. 
A decision-support system to trade-off analysis was validated to allow managers to insert any quantitative and qualitative methods. This research collaborates to aim the future researches in supply chain management and performance analysis as proposed in the conceptual model of this work.

This framework, used in association with traditional management philosophies, is a powerful tool that permits managers to develop a trade-off analysis and make decisions on workstations. Thus, a research field that correlates time variability with performance dimensions may be validated by this framework.

The trade-off analysis in this study is limited to a constant trade-off model to validate the framework. To help managers make better decisions, multi-objective models may be applied in discrete event systems. Further, the framework may be applied to continuous production without any model update.

\section{REFERENCES}

Aghezzaf, E.H., Jamali, M.A. and Ait-Kadi, D. (2007), "An integrated production and preventive maintenance", European Journal of Operational Research, Vol. 181, No. 2, pp. 679-85.

Ahmed, D.M. and Beauchamp-ElMaraghy, H. (2013), "Cost performance dynamics in lean production levelling", Journal of Manufacturing Systems, Vol. 8, No. 3, pp. 262-89.

Alan, C.E. and Beckett, J. (2000), "Implementing an industrial continuous improvement system: a knowledge management case study", Industrial Management \& Data Systems, Vol. 100, No. 7, pp. 330-8.

Andersson, M.B.C. and Bellgran, M. (2015), "On the complexity of using performance measures: Enhancing sustained production improvement capability by combining oee and productivity", Journal of Manufacturing Systems, Vol. 35, pp. 144-54.

Arinez, J., Biller, S., Meerkov, S.M. et al. (2010), "Quality/quantity improvement in an automotive", IEEE Transactions on Automation Science and Engineering, Vol. 7, No. 4, pp. 755-61.

Asgari, N., Nikbakhsh, E., Hill, A. et al. (2016), "Supply chain management 1982-2015: a review", IMA Journal of Management Mathematics, Vol. 27, No. 3, pp. 353-79.

Banasik, A., Bloemhof-Ruwaard, J.M., Kanellopoulos, A. et al. (2018), "Multi-criteria decision making approaches for green supply chains: a review", Flexible Services and Manufacturing Journal, Vol. 30, No. 3, pp. 366-96.

Başak, O. and Albayrak, Y.E. (2015), "Petri net based decision system modeling in real-time scheduling and control of flexible automotive manufacturing systems", Computers \& Industrial Engineering, Vol. 86, pp. 116-26.

Bokrantz, J., Skoogh, A., Lämkull, D. et al. (2018), "Data quality problems in discrete event simulation of manufacturing operations", Simulation: Transactions of the Society for Modeling and Simulation International, Vol. 94, No. 11, pp. 1009-25.

Castro, D.M. and Parreiras, F.S. (2018), "A review on multi-criteria decision-making for energy efficiency in automotive engineering", Applied Computing and Informatics. In press.

Chavez, R., Yu, W., Gimenez, C. et al. (2015), "Customer integration and operational performance: The mediating role of information quality", Decision Support Systems, Vol. 80, pp. 83-95.

Choe, K., Booth, D. and Hu, M. (1997), "Production competence and its impact on business performance", Journal of Manufacturing Systems, Vol. 16, No. 6, pp. 409-21.

Coelho, L., Lange, L. and Coelho, H. (2016), "Multi-criteria decision making to support waste management: a critical review of current practices and methods", Waste Management \& Research, Vol. 35, No. 10.

Colledani, M., Tolio, T., Fischer, A. et al. (2014), "Design and management of manufacturing systems for production quality", CIRP Annals Manufacturing Technology, Vol. 63, pp. 773-96.

Danesh, D., Ryan, M. and Abbasi, A. (2017), "Multi-criteria decision-making methods for project portfolio management: a literature review", International Journal of Management and Decision Making, Vol. 17, No. 1, pp. 75.

Davidrajuh, R. (2018), Modeling Discrete-Event Systems with GPenSIM, Springer International Publishing, Cham, $138 \mathrm{p}$.

Drakaki, M. and Tzionas, P. (2017), "Manufacturing scheduling using colored petri nets and reinforcement learning", Applied Sciences, Vol. 7, No. 2, pp. 136. 
El Mouayni, I., Etienne, A., Lux, A. et al. (2020), "A simulation-based approach for time allowances assessment during production system design with consideration of worker's fatigue, learning and reliability", Computers \& Industrial Engineering, Vol. 139, 105650.

Emery, C.R. (2009), "A cause-effect-cause model for sustaining cross-functional integration", Business Process Management Journal, Vol. 15, No. 1, pp. 93-108.

Fang, C. and Marle, F. (2012), "A simulation-based risk network model for decision support in project", Decision Support Systems, Vol. 52, No. 3, pp. 635-44.

Ferro, R., Ordóñez, R.E.C. and Anholon, R. (2017), "Analysis of the integration between operations management manufacturing tools with discrete event simulation", Prod. Eng. Res. Devel., Vol. 11, No. 4-5, pp. 467-76.

Franke, U. and Ciccozzi, F. (2018), "Characterization of trade-off preferences between non-functional properties", Information Systems, Vol. 74, No. 2, pp. 86-102.

Gardner, J.W. (2020), "Managing production yields and rework through feedback on speed, quality, and quantity", Production and Operations Management, Vol. 29, No. 9, pp. 2182-209.

Gebennini, E., Grassi, A., Fantuzzi, C. et al. (2017), "Discrete time model of a two-station one-buffer serial system with inventory level-dependent operation", Computers \& Industrial Engineering, Vol. 113, pp. 46-63.

Grosswiele, L., Röglinger, M. and Friedl, B. (2013), "A decision framework for the consolidation of performance measurement systems", Decision Support Systems, Vol. 54, No. 2, pp. 1016-29.

$\mathrm{Hu}, \mathrm{W}$. and He, X. (2014), "An innovative time-cost-quality tradeoff modeling of building construction project based on resource allocation", The Scientific WorldJournal, Vol. 2014, 673248.

Kannan, V.R. and Tan, K.C. (2005), "Just in time, total quality management, and supply chain management: understanding their linkages and impact on business performance", Omega, Vol. 33, No. 2, pp. 153-62.

Karmarkar, U. and Kekre, S. (1987), "Manufacturing configuration, capacity and mix decisions considering operational costs", Journal of Manufacturing Systems, Vol. 6, No. 4, pp. 315-24.

Kaya, İ., Çolak, M. and Terzi, F. (2018), "Use of MCDM techniques for energy policy and decision-making problems: a review", International Journal of Energy Research, Vol. 42, No. 7, pp. 2344-72.

Kempenaers, J., Pinte, J., Detand, J. et al. (1996), "A collaborative process planning and scheduling", Advances in Engineering Software, Vol. 25, No. 1, pp. 3-8.

Kim, Y.H., Sting, F.J. and Loch, C.H. (2014), "Top-down, bottom-up, or both? toward an integrative perspective on operations strategy formation", Journal of Operations Management, Vol. 32, No. 7-8, pp. 462-74.

Layeb, S.B., Jaoua, A., Jbira, A. et al. (2018), "A simulation-optimization approach for scheduling in stochastic freight transportation", Computers \& Industrial Engineering, Vol. 126, pp. 99-110.

MacCormack, A., Kemerer, C.F., Cusumano, M. et al. (2003), "Trade-offs between productivity and quality in selecting software development practices", IEEE Software, Vol. 20, No. 5, pp. 78-85.

MacKenzie, D.I., Nichols, J.D., Royle, J.A. et al. (2018), Occupancy Estimation and Modeling, 2nd ed., Academic Press, London, pp. 71-111z

Madapusi, A. and D'Souza, D. (2012), "The influence of ERP system implementation on the operational performance of an organization", International Journal of Information Management, Vol. 32, No. 1, pp. 24-34.

Mardani, A., Jusoh, A., Halicka, K. et al. (2018), "Determining the utility in management by using multi-criteria decision support tools: a review", Economic Research-Ekonomska Istraživanja, Vol. 31, No. 1, pp. 1666-716.

Mitra, S., Karathanasopoulos, A., Sermpinis, G. et al. (2015), "Operational risk: Emerging markets, sectors and measurement", European Journal of Operational Research, Vol. 241, No. 1, pp. 122-32.

Moktadir, M.A., Ali, S.M., Paul, S.K. et al. (2019), "Barriers to big data analytics in manufacturing supply chains: a case study from Bangladesh", Computers \& Industrial Engineering, Vol. 128, pp. 1063-75.

Montgomery, D.C. (2019), Introduction to Statistical Quality Control, 8th ed., Wiley, Hoboken, 768 p.

Mrad, M., Al-Gahtani, K.S., Hulchafo, R. et al. (2019), "Risk assessment for discrete stochastic time-costquality trade-off problem using simulation-based integer linear programming approach", IEEE Access: Practical Innovations, Open Solutions, Vol. 7, pp. 32453-63.

Müller, R. and Oehm, L. (2019), "Process industries versus discrete processing: how system characteristics affect operator tasks", Cognition Technology and Work, Vol. 21, No. 2, pp. 337-56.

Murata, T. (1989), "Petri nets: properties, analysis and applications", Proceedings of the IEEE, Vol. 77, No. 4, pp. 541-80. 
Negahban, A. and Smith, J.S. (2014), "Simulation for manufacturing system design and operation: Literature review and analysis", Journal of Manufacturing Systems, Vol. 33, No. 2, pp. 241-61.

Neha, P. and Ashutosh, T. (2017), "A review of assembly optimisation applications using discrete event simulation", International Journal of Computer Integrated Manufacturing, Vol. 30, pp. 2-3, 215-28.

Okoli, C. and Pawlowski, S.D. (2004), "The Delphi method as a research tool: an example, design considerations and applications", Information \& Management, Vol. 42, No. 1, pp. 15-29.

Parast, M. (2011), "The effect of six sigma projects on innovation and firm performance", International Journal of Project Management, Vol. 29, No. 1, pp. 45-55.

Plaza, M., Zebala, W. and Matras, A. (2019), "Decision system supporting optimization of machining strategy", Computers \& Industrial Engineering, Vol. 127, pp. 21-38.

Popoli, P. (2019), "Designing management control systems: systemic vs sectoral approach", International Journal of Business and Management, Vol. 14, No. 6, pp. 130.

Popović, M., Kuzmanović, M. and Savić, G. (2018), "A comparative empirical study of analytic hierarchy process and conjoint analysis: literature review", Decision Making: Applications in Management and Engineering, Vol. 1, No. 2, pp. 153-63.

Prajogo, D., Toy, J., Bhattacharya, A. et al. (2018), "The relationships between information management, process management and operational performance: internal and external contexts", International Journal of Production Economics, Vol. 199, pp. 95-103.

Proehl, R.A. (1996), "Enhancing the effectiveness of cross-functional teams", Leadership and Organization Development Journal, Vol. 17, No. 5, pp. 3-10.

Puche, J., Ponte, B., Costas, J. et al. (2016), "Systemic approach to supply chain management through the viable system model and the theory of constraints", Production Planning and Control, Vol. 27, No. 5, pp. 421-30.

Rivera-Gómez, H., Gharbi, A., Kenné, J.-P. et al. (2020), "Joint optimization of production and maintenance strategies considering a dynamic sampling strategy for a deteriorating system", Computers \& Industrial Engineering, Vol. 140, 106273.

Robson, K., Maclntyre, J. and Trimble, R. (2013), "Measuring the status and alignment of maintenance and manufacturing strategies: the development of a new model and diagnostic tool", Journal of Quality in Maintenance Engineering, Vol. 19, No. 4, pp. 381-97.

Rosenzweig, E. and Easton, G. (2010), "Tradeoffs in manufacturing? a meta-analysis andcritique of the literature", Production and Operations Management, Vol. 19, No. 2, pp. 127-41.

Sant'Anna, A.M.O. (2015), "Framework of decision in data modeling for quality improvement", The TQM Journal, Vol. 27, No. 1, pp. 135-49.

Santa, R., Ferrer, M., Bretherton, P. et al. (2010), "Contribution of cross-functional teams to the improvement in operational performance", Team Performance Management, Vol. 16, No. 3-4, pp. 148-68.

Sartal, A., Llach, J., Vázquez, J.H. et al. (2017), "How much does lean manufacturing need environmental and information technologies", Journal of Manufacturing Systems, Vol. 45, pp. 260-72.

Schardong, G.G., Rodrigues, A.M.B., Barbosa, S.D.J. et al. (2018), "Visual interactive support for selecting scenarios from time-series ensembles", Decision Support Systems, Vol. 113, pp. 99-107.

Sousa, W.T.J., Montevechi, J.A.B., Miranda, R.C. et al. (2018), "Discrete simulation-based optimization methods for industrial engineering problems: a systematic literature review", Computers \& Industrial Engineering, Vol. 128, pp. 526-40.

Swink, M., Narasimhan, R. and Kim, S.W. (2005), "Manufacturing practices and strategyintegration: effects on cost efficiency,flexibility, and market-based performance", Journal of Decision Sciences, Vol. 36, No. 3, pp. 427-57.

Tan, J. and Wang, L. (2010), "Flexibility-efficiency tradeoff and performance implications among chinese soes", Journal of Business Research, Vol. 63, No. 4, pp. 356-62.

Vivas, R.C., Sant'Anna, A.M.O., Esquerre, K.P.S.O. et al. (2020), "Integrated method combining analytical and mathematical models for the evaluation and optimization of sustainable supply chains: a Brazilian case study", Computers \& Industrial Engineering, Vol. 139, 105670.

Wang, H., Jiang, Z., Zhang, H. et al. (2019a), "An integrated MCDM approach considering demandsmatching for reverse logistics", Journal of Cleaner Production, Vol. 208, pp. 199-210. 
Wang, S., Wang, X. and Zhang, J. (2019b), "A review of flexible processes and operations", Production and Operations Management. In press.

Wang, Y., Wallace, S.W., Shen, B. et al. (2015), "Service supply chain management: a review of operational models", European Journal of Operational Research, Vol. 247, No. 3, pp. 685-98.

Weinstein, L. and Chung, C. (1999), "Integrating maintenance and production decisions in a hierarchical production planning environment", Computers \& Operations Research, Vol. 26, No. 10-11, pp. 1059-74.

Weiss, B.A., Sharp, M. and Klinger, A. (2018), "Developing a hierarchical decomposition methodology to increase manufacturing process and equipment health awareness", Journal of Manufacturing Systems, Vol. 48, pp. 96-107.

Xu, Z., Ming, X.G., Song, W. et al. (2014), "Collaborative project management: a systemic approach to heavy equipment manufacturing project management", Systemic Practice and Action Research, Vol. 27, No. 2, pp. 141-64.

Yang, D., Li, X., Jiao, R.J. et al. (2018), "Decision support to product configuration considering component replenishment uncertainty: A stochastic programming approach", Decision Support Systems, Vol. 105, pp. 108-18.

Yegul, M.F., Erenay, F.S., Striepe, E. et al. (2017), "Improving configuration of complex production lines via simulation-based optimization", Computers \& Industrial Engineering, Vol. 109, pp. 295-312.

Yu, D., Wang, R., Zhang, W. et al. (2018), "A bibliometric analysis of research on multiple criteria decision making", Current Science, Vol. 114, No. 4, pp. 747-58.

Author contributions: All authors contributed equally to this paper. 